\title{
Pregnancy and early onset pauciarticular juvenile chronic arthritis
}

Elzbieta Musiej-Nowakowska, Rafal Ploski

\begin{abstract}
Objectives-To study interaction of early onset pauciarticular juvenile chronic arthritis (EOP-JCA) and pregnancy in the Polish population, in particular to confirm the ameliorating effect of pregnancy on disease activity reported by others and to analyse the factors that govern the occurrence of postpartum flare, with emphasis on the potential role of breast feeding.

Methods-The reproductive outcome and disease status in 39 adult women with history of EOP- JCA was examined by means of a questionnaire and an interview. In all patients the disease onset occurred before the 6th birthday, 19 had persistent pauciarticular JCA (PeEOP-JCA) and $20 \mathrm{had}$ extended pauciarticular JCA (ExEOPJCA).
\end{abstract}

Results-23 women had at least one successful pregnancy, seven had unsuccessful pregnancies but all of them had also one or more successful pregnancies. Among those who have never been pregnant $(n=16)$ there was a higher frequency of eye disease and ExEOP-JCA compared with the rest of the group. In almost all cases pregnancy was associated with remission of disease activity, however a postpartum flare appeared after 22 pregnancies $(52 \%)$. The flares were more frequent in women who had an active disease before pregnancy, had a flare after a previous pregnancy and/or were breast feeding.

Conclusions-In EOP-JCA patients pregnancy generally has a good outcome and induces amelioration of disease activity. After delivery, however, a flare of disease often appears, especially in women who were breast feeding, had a postparum flare previously or had an active disease before pregnancy. The pattern of interaction between disease and pregnancy found in EOP-JCA makes EOP-JCA similar in this respect to $R A$, but different from systemic lupus erythematosus and ankylosing spondylitis.

(Ann Rheum Dis 1999;58:475-480)

Presence of connective tissue disease may significantly influence the course and outcome of human pregnancy, also pregnancy may have a distinct modifying influence on activity of the disease. Interestingly, the exact pattern of interaction between pregnancy and disease varies. For example, women with systemic lupus erythematosus (SLE) have an increased incidence of abortion, stillbirths, and perinatal deaths whereas none of these are typical for rheumatoid arthritis (RA). ${ }^{1-3}$ There are also differences concerning the influence of pregnancy on disease activity. In RA there is a reduction of disease activity during pregnancy, often followed by a relapse in the postpartum period. ${ }^{4-9}$ In contrast, the clinical course of ankylosing spondylitis (AS) remains unchanged or worsens throughout gestation ${ }^{6} 1011$ and in SLE the severity of the disease generally increases during pregnancy.

An interesting association between breast feeding and development of disease in the postpartum period was reported in RA. ${ }^{12}$ Also an association between breast feeding and a severe course in RA was demonstrated. ${ }^{18}$ It was proposed that high levels of prolactin might be responsible for this phenomenon. $^{12} 1318$

There is a limited amount of information published regarding fertility and pregnancy outcomes in juvenile chronic arthritis (JCA). One study showed that, although women with history of JCA were advised against pregnancy significantly more frequently than controls, there were no statistically significant differences between the cases and controls regarding the number of pregnancies, live births and miscarriage rates. ${ }^{14}$ Other authors concluded that fetal and maternal outcome of pregnancy of women, who have had JCA, is good, but JCA was associated with a higher frequency of caesarean section, with bilateral hip prosthesis as the main cause..$^{1516}$

The influence of pregnancy on disease activity in JCA has not been extensively investigated either. The only reported study comes from Norway and includes the experience of 76 pregnancies in 51 patients (later extended to 61 patients and 92 pregnancies). ${ }^{10}{ }^{15}$ The studied group consisted of all subtypes of JCA and the early and late onset pauciarticular JCA were not analysed separately. It was shown that inactive disease was not reactivated during pregnancy. In patients with moderate joint symptoms or active disease at conception, 
improvement was experienced in about $60 \%$ of the pregnancies and worsening in only $9 \%$ of pregnancies. Improvement was more common in patients with polyarticular JCA than in cases with pauciarticular JCA or systemic disease.

A postpartum flare was observed three to six months after delivery following up $58 \%$ of the pregnancies. $^{81516}$ However, the factors influencing its occurrence, in particular the potential role of breast feeding, were not systematically studied.

To study interaction of JCA and pregnancy in the Polish population, we examined the reproductive outcome and disease status in 39 women with history of early onset pauciarticular JCA (EOP-JCA), which is the most frequent and most homogeneous subset of JCA. We were especially interested in confirming the strong ameliorating effect of pregnancy on disease activity and in analysing the factors that govern the occurrence of postpartum flare, with emphasis on the potential role of breast feeding.

\section{Methods}

PATIENTS

A group of 54 women with EOPA-JCA, of whom $39(72 \%)$ expressed an interest in participating in the study was selected. These patients were originally identified during the period from 1962 to 1980 in the Paediatric Clinic of the Institute of Rheumatology in Warsaw, for the purpose of other studies. All patients satisfied ARA (ACR) criteria for JRA. ${ }^{17}$ Disease duration was at least 15 years.

All patients had the disease onset before their 6th birthday and all had a pauciarticular joint involvement (four or less joints) during the first six months after diagnosis. Nineteen patients had persistent pauciarticular EOPJCA (PeEOP-JCA, four or fewer joints involved throughout disease duration) and 20 had extended EOP-JCA (ExEOP-JCA, cumulative total of five or more joints involved after at least six months course).

For the purpose of the study patients were called in and examined by one of us (EMN). Their histories were reviewed, the past and current status of the ocular and articular disease as well as the incidence of antinuclear antibodies (ANA) was assessed. All the patients were examined for manifestations of RA, spondyloarthropathies and SLE but the diagnosis (EOP- JCA) was not changed in any of the cases. In particular none of the patients was more than once positive for rheumatoid factor (RF) and none had anti-DNA anti-Sm or RnP antibodies (although in some cases these tests were not performed). Furthermore, none of the patients had rheumatoid nodules, sacroilitis or enthesitis. The retrospective data were obtained from the hospital records, through a questionnaire and a personal interview when necessary.

The following definitions were used in the clinical assessment of the patients:

Active disease-presence of painful and/or tender joints, swelling, active synovitis or iridocyclitis requiring drug treatment (NSAIDs or DMARDs, or both, for at least one month) and excluding pain from damage alone (that is, the mechanical pain).

Improvement - no joint pain (except for mechanical pain), no evidence of active synovitis or iridocyclitis, without drugs for less than three months.

Inactive disease-no joint pain (except for mechanical pain), no evidence of active synovitis or iridocyclitis, without drugs for more than three months but less than two years.

Remission-no joint pain (except for mechanical pain), no evidence of active synovitis or iridocyclitis and without drugs for more than two years.

Flare-recurrence of disease after a disease free interval of at least six months without medication.

\section{STATISTICAL METHODS}

Binomial variables were analysed with the $\chi^{2}$ test or Fisher's exact test when appropriate. The first year mortality in Poland in the 1980s and the frequency of caesarean section in Poland were treated as known values in calculation of the $\chi^{2}$. Continuous variables were analysed with Student's $t$ test. $\chi^{2}$ Test for a trend in proportion was performed using Epi-Info 6.0 software. Relative risk (RR) was calculated by the method of Woolf-Haldane.

\section{Results}

FREQUENCY AND THE OUTCOME OF PREGNANCY The group included in the study comprised 39 women who have been followed up for a mean (SD) of 28.1 (7) years, 21 (54\%) were ANA positive and $23(59 \%)$ had chronic iridocyclitis. Table 1 shows the characteristics of the patients in relation to the reproductive outcome.

There were 23 women (59\%) who had at least one successful pregnancy (that is, resulting in the birth of a baby who lived through the neonatal period of 30 days). Nine pregnancies $(21 \%)$ were delivered by caesarean sections, in six cases this was because of sequels of JCA (contracted pelvis and changes in the hip joints

Table 1 Characteristics of the patients stratified according to reproductive outcome

\begin{tabular}{lllll}
\hline & & $\begin{array}{l}\text { Women all of whose } \\
\text { Wregnancies were } \\
\text { successful }(n=16)\end{array}$ & $\begin{array}{l}\text { Women with one or } \\
\text { more spontaneous } \\
\text { abortion or first month } \\
\text { child death }(n=7)\end{array}$ & $\begin{array}{l}\text { Women without } \\
\text { pregnancy }(n=16)\end{array}$ \\
\hline Age (y, mean (SD)) & $33.8(5.1)$ & $32.7(5.4)$ & $36.4(3.5)$ & $25.7(6.4) \dagger$ \\
Disease duration (y, mean (SD)) & $31.4(5.3)$ & $30.2(5.5)$ & $34.4(3.2)$ & $23.6(9.0) \dagger$ \\
ANA (n) (\%) & $12(52)$ & $6(38)$ & 6 & 9 \\
Chronic iridocyclitis (n) (\%) & $10(43)$ & $8(50)$ & $2(29)$ & $13(5)$ \\
$(81)^{\star}$ & \\
\hline
\end{tabular}

${ }^{\star} \mathrm{p}<0.05, \mathrm{RR}=5.6$ for the comparison of women with pregnancy $v$ women without pregnancy $\left(\chi^{2}\right.$ test $) .+\mathrm{p}<0.002$ for the comparison of women with pregnancy $v$ women without pregnancy (Student's $t$ test). $\ddagger \mathrm{p}=0.07$ for the comparison of women with all successful pregnancies $v$ women with one or more unsuccessful pregnancies (Fisher's exact test). 
(two women, three pregnancies) or severe ocular damage (danger of retinal detachment, one woman, three pregnancies).

Seven women had unsuccessful pregnancies. These included six spontaneous abortions in five women and two perinatal deaths (one because of prematurity and the other because of volvulus). Six women with unsuccessful pregnancy(ies) also had one or more successful pregnancy. There was a trend for higher frequency of ANA positivity among women with unsuccessful pregnancies (table 1).

Sixteen women $(41 \%)$ have not reported ever being pregnant. The frequency of chronic iridocyclitis was significantly higher in this group as compared with the rest of the patients (table 1). The patients who had not been pregnant were also younger and had shorter average disease duration compared with the remaining patients (table 1). One woman in this group reported a fertility problem whereas the remaining declared that the lack of pregnancy was caused by their decision.

Table 2 gives the reproductive outcome as well as characteristics of the patients in relation to the type of disease (that is, PeEOP-JCA $v$ ExEOP-JCA). Among the patients with ExEOP-JCA, there were significantly fewer women who reported a pregnancy, compared with the group with PeEOP-JCA. However, the average number of children per woman, among those who were pregnant, was similar in both groups (table 2). The ExEOP-JCA had higher frequency of caesarean sections compared with PeEOP-JCA, but the difference was not statistically significant. There were no statistically significant differences between the two groups with regard to age, duration of disease,

Table 2 Characterisation of the patients and their reproductive outcome in relation to the type of disease

\begin{tabular}{lll}
\hline & PeEOP-FCA $(n=19)$ & ExEOP-FCA $(n=20)$ \\
\hline $\begin{array}{l}\text { Women who were pregnant (n) (\%) } \\
\text { Total pregnancies (n) }\end{array}$ & $15(79)^{\star}$ & $8(40)$ \\
$\begin{array}{l}\text { Average number of pregnancies among } \\
\quad \text { those who were pregnant }\end{array}$ & $32 \dagger$ & 18 \\
Spontaneous abortions (abortion/woman) & $3 / 1$ & 2.3 \\
Sick children (children/women) & $3 / 3$ & $3 / 2$ \\
Caesarean section (n) (\%) & $3(16)$ & $2 / 2$ \\
Age, mean (SD) (y) & $31.9(5.8)$ & $6(30)$ \\
JCA duration mean (SD) (y) & $29.3(5.9)$ & $29.1(7.9)$ \\
Chronic anterior uveitis (n) (\%) & $10(53)$ & $13.0(7.9)$ \\
ANA positivity (n) (\%) & $10(53)$ & $11(55)$ \\
\hline
\end{tabular}

${ }^{\star} \mathrm{p}<0.05 \mathrm{RR}=5.6$ for the comparison with ExEOP-JCA $\left(\chi^{2}\right.$ test $) .+$ Includes two selective abortions.

Table 3 Disease activity during pregnancy in relation to disease type and activity before pregnancy

\begin{tabular}{lclcc}
\hline \multicolumn{5}{c}{ FCA activity during pregnancy } \\
\cline { 3 - 5 } Before pregnancy & $(n)$ & $\begin{array}{l}\text { worsening } \\
(n)(\%)\end{array}$ & $\begin{array}{l}\text { no change } \\
(n)(\%)\end{array}$ & $\begin{array}{c}\text { improvementt } \\
(n)(\%)\end{array}$ \\
\hline PeEOP in remission & 17 & $1(6)$ & $16(94)$ & 0 \\
PeEOP active & 9 & 0 & 0 & $9(100)$ \\
ExEOP in remission & 9 & 0 & $9(100)$ & 0 \\
ExEOP active & 7 & 0 & $1(14)$ & $6(86)$ \\
All in remission & $26^{\star}$ & $1(4)$ & $25(96)$ & 0 \\
All active & 16 & 0 & $1(6)$ & $15(94)$ \\
All PeEOP & 26 & $1(4)$ & $16(62)$ & $9(35)$ \\
All ExEOP & 16 & 0 & $10(63)$ & $6(38)$ \\
Total & 42 & $1(2)$ & $26(62)$ & $15(36)$ \\
\hline
\end{tabular}

tIn all but one case there was inactivation of disease. ${ }^{\star} \mathrm{p}<0.0001$ for the comparison of the frequency of inactive disease before pregnancy $(26 / 42,62 \%) v$ the frequency of inactive disease during pregnancy $(40 / 42,95 \%)$. prevalence of chronic iridocyclitis or ANA (table 2).

STATUS OF CHILDREN

There were altogether 43 children (27 girls and 16 boys) born by women who participated in the study (including one pair of twins). Apart from one baby who died in the neonatal period there were no premature or small for date babies. At the time of the study 35 of the children were more than 1 year old.

In addition to the two perinatal deaths mentioned in previous section, there was one more death: a child with chromosomal abnormalities died in the third month of life. The mother of the child had been in complete remission for a long time and was not taking any drugs. At the onset of the disease she had used prednisolone (for two months) and later, gold and NSAIDs.

One boy developed pauciarticular JCA at the age of three. His mother had ExEOP-JCA and a year before getting pregnant she underwent kidney transplantation because of renal insufficiency (because of chronic glomerulonephritis coexisting with JCA in this patient). Before and during pregnancy she had used prednisolone, azathioprine and cyclosporine.

In another child, whose mother had PeEOPJCA, a mild inborn heart defect was diagnosed.

The remaining children were healthy.

ACTIVITY OF JCA DURING PREGNANCY

Table 3 shows disease activity during pregnancy in relation to disease type and activity before pregnancy.

Before pregnancy 16 patients (38\%) had active disease. They took standard doses of salazopyrin (5 women), penicillamine (2 women), NSAIDs (8 women) or prednisolone, azathioprine and cyclosporine (the woman with renal transplant). Among 14 (88\%) patients from this group there was inactivation of disease during pregnancy and in one case $(6 \%)$, a considerable improvement. There was only one patient (with ExEOP-JCA) who experienced no change of disease activity during pregnancy. Except for the woman with renal transplant, all women stopped taking drugs. Only in one case, after cessation of therapy (salazopyrin), a relapse of disease appeared (synovitis of the knee), which, however, responded well to intra-articular glucocorticoids.

Twenty six women $(62 \%)$ had disease remission before pregnancy. Except for one woman (with PeEOP-JCA) who had an episode of arthritis of the knee, all the patients from this group $(96 \%)$ did not experience reactivation of JCA.

In the whole group, the frequency of inactive disease during pregnancy was significantly higher than the frequency of inactive disease before pregnancy (respectively, 40 of $42,95 \% v$ 26 of $42,62 \%, \mathrm{p}<0.0001$, table 3$)$.

Analysis of the patients stratified by the subtype of disease (PeEOP-JCA $v$ ExEOP-JCA) did not reveal significant differences (table 3).

None of the 10 patients with chronic iridocyclitis had exacerbation of the ocular disease during pregnancy. 
ACTIVITY OF JCA AFTER PREGNANCY-

POSTPARTUM FLARE

A postpartum flare of disease activity was noted within one year after delivery following 22 pregnancies $(52 \%)$. In six cases $(27 \%)$ the flare appeared during the third month after delivery, in one case $(5 \%)$ between the third and sixth month, and in the remaining 15 cases (68\%) after the sixth month after delivery. In 19 patients the flares consisted of articular exacerbations, in two patients there were exacerbations of chronic iridocyclitis, and in one patient there was an exacerbation of both the articular and ocular disease. In none of the patients was the disease permanently reactivated.

Table 4 shows the frequency of the postpartum flare in relation to disease type and activity before pregnancy. It can be seen that the flares were statistically significantly more frequent in women who had an active disease before pregnancy. Although we did not study it systematically we noted that the duration and severity of the flares were relatively higher among these patients. There was also a trend for a more frequent occurrence of the flares among patients with ExEOP-JCA compared with PeEOP-JCA but this was not statistically significant (table 4).

We observed that when a woman had a flare after one pregnancy she was likely to experience it in the following pregnancies. Nine of 10 women $(90 \%)$ who had a postpartum flare after previous (that is, first or second) pregnancy also had a flare after the following pregnancy (that is, respectively, second or third) whereas among women who did not experience flare in previous pregnancies, the frequency of flare in the following pregnancy was 33\% (3 of 9 ). The difference between the frequency of flare in the two groups was statistically significant $(9$ of $10(90 \%)$ v 3/9 (33\%), p<0.02).

We did not observe a statistically significant correlation between the incidence of flare and the cumulative number of previous pregnancies, although there was a trend $\left(p=0.09, \chi^{2}\right.$ for a linear trend in proportions, data not shown). Also, there was a trend ( $p=0.12$, Fisher's exact test) for the association between ANA positivity and postpartum flare $(66 \%, 14$ of 21 v $38 \%$, 8 of 21 , respectively, for the frequency of postpartum flares among ANA positive and negative patients).

Table 4 Frequency of the postpartum flare in relation to disease type and ativity before pregnancy

\begin{tabular}{lrc}
\hline Disease before pregnancy & $n$ & $\begin{array}{c}\text { Postpartum flare } \\
\text { frequency } n(\%)\end{array}$ \\
\hline PeEOP in remission & 17 & $5(29)$ \\
PeEOP active & 9 & $6(67)$ \\
ExEOP in remission & 9 & $5(56)$ \\
ExEOP active & 7 & $6(86)$ \\
All PeEOP & 26 & $11(42)$ \\
All ExEOP & 16 & $11(69)$ \\
All active & 16 & $12(75)^{\star}$ \\
All in remission & 26 & $10(39)$
\end{tabular}

${ }^{\star} \mathrm{p}<0.05, \mathrm{RR}=4.8$ for the comparison of frequencies of the postpartum flare in patients with active disease before pregnancy $v$ those in remission before pregnancy.
Table 5 Incidence of postpartum flare in relation to the cumulative number of breast fed children (including the previous pregnancies and the current one)

\begin{tabular}{lllll}
\hline Breast fed children & 0 & 1 & 2 & 3 \\
\hline Pregnancies (n) & 5 & 18 & 10 & 3 \\
Flare (n) (\%) & 0 & $8(44)$ & $7(70)$ & $3(100)$
\end{tabular}

$-8(44)-7(7)$

ASSOCIATION BETWEEN BREAST FEEDING AND

POSTPARTUM FLARE

We found evidence indicating that a link exists between occurrence of postpartum flares and breast feeding.

The data about breast feeding could be obtained for 20 women who gave birth to 37 babies (including one pair of twins). Thirty one babies were breast fed and five were not. None of the women who did not breast feed had a postpartum flare, whereas in the remaining group the flare occurred in 18 (58\%) cases. The difference between the incidence of postpartum flare among those who did not breast fed and the remaining group was statistically significant (58\% (18 of 31) $v 0$ (0 of 5) $\mathrm{p}<0.025, \mathrm{RR}=17.6)$.

There was also a correlation between the incidence of postpartum flare and the total number of children breast fed by a woman (that is, during previous pregnancies and the current one). Table 5 shows the data. As can be seen, the incidence of postpartum flare increased approximately linearly in proportion to the cumulative number of breast fed children $(\mathrm{p}<0.003)$.

The duration of breast feeding did not correlate with the occurrence of flare. The frequency of postpartum flare was not statistically significantly different between women who had breast fed for less than six months (66.7\%) and the remaining group (47.1\%).

We noted that postpartum flare did not occur in any of the patients during the period of exclusive breast feeding but either after cessation of breast feeding or in the period of mixed feeding. Seven (39\%) women had a flare within the first month after cessation of breast feeding, two (11\%) between the second and third month, two (11\%) during the ninth month. Three $(17 \%)$ women had a flare in the period of mixed feeding. Four (22\%) women did not remember the exact timing of the flare relative to cessation of breast feeding but were positive that it occurred after the period of exclusive breast feeding.

\section{Discussion}

We analysed the reproductive outcome as well as interaction between disease activity and pregnancy in a group of 39 adult women with EOP-JCA. The most interesting findings include the strong disease ameliorating effect of pregnancy, relatively frequent incidence of postpartum flare as well as the association between its occurrence and breast feeding, disease activity before pregnancy and previous history of post-pregnancy exacerbations.

The strong ameliorating effect of pregnancy on the activity of JCA has also been shown by Ostensen. ${ }^{15}$ Thus, the available data indicate 
that in respect to the effect of pregnancy on the inflammatory activity, JCA is similar to RA but different from spondyloartropathies and SLE whose course, respectively, worsens or does not change during pregnancy. ${ }^{12-11}$ It is not clear what differences in pathogenesis of these disorders are responsible for their different interaction with pregnancy.

Our study confirms the relatively frequent occurrence of postpartum flare in EOP-JCA reported by Ostensen. ${ }^{15}$ The association between flare after the current pregnancy and history of flare in previous pregnancies found by us is also compatible with the results of Ostensen who noted a trend for a more severe course of postpartum flare in subsequent pregnancies compared with the first one. ${ }^{15}$ The difference between the two studies is the correlation between pre-pregnancy disease activity and occurrence of flare found by us but not by Ostensen. ${ }^{15}$ The reasons for this discrepancy are not clear. However, it should be noted that the group of patients studied by Ostensen included not only EOP-JCA but also a unspecified number of cases of late onset pauciarticular JCA as well as cases of AS. ${ }^{15}$ Thus, it is possible that the differences between the two studies are caused by differences in the selection of patients.

The data on the influence of breast feeding and the occurrence of postpartum flare in EOP-JCA were not reported before. We found an association between breast feeding and occurrence of flare as well as the correlation between a cumulative number of breast fed children and the occurrence of flare. It is interesting to note that a number of studies in RA patients showed that breast feeding might be associated with worsening or even onset of disease. It was shown that women who breast feed had a fivefold increase in the risk of developing RA within 12 months after pregnancy compared with controls. ${ }^{9}$ It was also demonstrated that among the RA patients, duration of breast feeding, and the number of breast fed children were significantly increased in those with severe disease compared with those with relatively mild RA. ${ }^{18}$

The proposed explanation was that during pregnancy prolactin levels increase along with levels of anti-inflammatory steroid hormones. In the postpartum period levels of these hormones fall rapidly to their pre-pregnancy levels, unless the mother is breast feeding, in which case prolactin level remains high. Prolactin has well known proinflammatory activity and it has been implicated in the pathogenesis of postpartum flare in an experimental model of collagen induced arthritis. ${ }^{19} 20$ Thus, it is possible, that also in some women with JCA, exposure to high levels of prolactin, unopposed by steroids, might act as the proinflammatory stimulus reactivating the disease. However, this theory does not quite fit our data because it does not explain the observation that the majority of flares occurred after cessation of breast feeding. Thus, it is likely that the mechanism of postpartum flare is more complex than previously anticipated.
The relatively high frequency of postpartum flares among JCA patients raises the question whether the patients should be discouraged from pregnancy. Because the flares were not very severe and, in particular, did not permanently reactivate the disease we do not think JCA patients should be advised against becoming pregnant. None the less, some consideration can be given to the advice against breast feeding as well as the possibility of prophylactic DMARDs treatment postpartum.

In agreement with previous studies ${ }^{14-16}$ our results show that EOP-JCA does not have a major adverse effect on the fertility or the outcome of pregnancy. The majority of women had become pregnant and the significantly younger age of those who had not suggests that at least some women from this group will become pregnant in the future. It is likely that in the majority of women who were not pregnant, this resulted from the expected inability to cope with the associated problems rather than from infertility (in our group only one woman reported a fertility problem). The associations between the lack of pregnancy on the one hand and the eye disease and polyarticular course of JCA on the other hand are also consistent with the view that the lack of pregnancy is mainly attributable to a decision caused by decreased functional ability of patients. In particular we noted that in many of our patients chronic iridocyclitis was quite severe and caused a significant impairment of vision (six patients were actually blind in one eye). Indeed, some of these patients admitted that the poor sight was a significant factor influencing them against becoming pregnant.

As also shown by other authors, in some JCA patients pelvic abnormalities or eye disease complicate the delivery and necessitate caesarean section. However, this was not a major problem among our patients: the frequency of caesarean section among the women studied by us was $21 \%$, which is not statistically significantly higher than the rate of caesarean section reported in Poland $\left(14 \%, \mathrm{p}=0.24, \chi^{2}\right.$ test $) .{ }^{21}$

As regards the status of children we did not find a major adverse effect of JCA. The first year mortality rate among children of the studied patients was 3 of $43(7 \%)$ and it was not statistically significantly higher than the general first year mortality rate in Poland in the 1980 s $\left(2.1 \%, p=0.11, \chi^{2}\right.$ test $) .^{22}$ Furthermore, the causes of death (prematurity, volvulus, chromosomal abnormality) do not form a pattern that would directly implicate the disease or medication as the cause.

What may be a matter of some concern is the increased risk of JCA in the offspring. In our series one child $(2 \%)$ developed JCA, whereas in the series of Ostensen there were two such cases $(2.6 \%)$. These figures are two orders of magnitude higher than the estimated prevalence of EOP-JCA in Europe (25-50 per $100000) .{ }^{23}{ }^{24}$ It is well recognised that genetic factors play a part in the development of $\mathrm{JCA}^{25}{ }^{26}$ however, larger studies are clearly needed to precisely define the heritable risk of disease. 
In conclusion, we found that in EOP-JCA patients pregnancy generally has a good outcome and induces amelioration of activity of disease. After delivery, however, a flare of JCA often appears, especially in women who were breast feeding, had a postpartum flare previously or had an active disease before pregnancy. The pattern of interaction between disease and pregnancy found in JCA makes JCA similar in this respect to RA but different from SLE and AS.

Funding: this work was supported by KBN Grant 4.P05.E.002.10.

1 Petri M. Hopkins lupus pregnancy center 1987 to 1996. Rheum Dis Clin North Am 1997:23:195-212.

2 Khamashta MA, Ruiz-Irastorza GR, Hughes GRV. Systemic lupus erythematosus flares during pregnancy. Rheum Dis Clin North Am 1997;23:15-30.

3 Spector TD, Silman AJ. Is poor pregnancy outcome a risk factor in rheumatoid arthritis? Ann Rheum Dis 1990;49: $12-40$.

4 Kaplan D, Diamond H. Rheumatoid arthritis and preg nancy. Clin Obstet Gynecol 1965;8:286-91.

5 Ostensen M, Aune B, Husby G. Effect of pregnancy and hormonal changes on the activity of rheumatoid arthritis. Scand J Rheumatol 1983;12:69-72.

6 Ostensen M, Husby G. A prospective clinical study on the effect of pregnancy on rheumatoid arthritis and ankylosing spondylitis. Arthritis Rheum 1983;26:1155-9.

7 Klipple GL, Cecere FA. Rheumatoid arthritis and pregnancy. Rheum Dis Clin North Am 1989;15:213-39.

8 Silva JA, Spector TD. The role of pregnancy on the course and aetiology of rheumatoid arthritis. Clin Rheumatol and aetiology of

9 Nelson JL, Ostensen M. Pregnancy and rehumatoid arthritis. Rheum Dis Clin North Am 1997;23:195-212.

10 Ostensen $M$. The effect of pregnancy on ankylosing spondylitis, psoriatic arthritis and juvenile rheumatoid arthritis. Am J Reprod Immunol 1992;28:235-7.

11 Ostensen M. Pregnancy in psoriatic arthritis. Scand J Rheumatol 1988;17:67-70

12 Brennan P, Silman A. Breast-feeding and the onset of rheumatoid arthritis. Arthritis Rheum 1994;37:808-13.
13 Brennan P, Ollier B, Worthington J, Hajeer A, Silman A. Are both genetic and reproductive associations with rheumatoid arthritis linked to prolactin? Lancet 1996;348:106-9.

14 Peterson LS, Mason T, Nelson AM, O'Fallon WM, Gabriel SF. Psychosocial outcomes and health status of adults who have had juvenile rheumatoid arthritis. Arthritis Rheum 1997;40:2235-40.

15 Ostensen M. Pregnancy in patients with history of juvenile rheumatoid arthritis. Arthritis Rheum 1991;34:881-7.

16 Ostensen M. Problems related to pregnacy in patients with juvenile chronic arthritis. Rev Rhum Engl Ed 1997;64 (suppl):196-7S.

17 Brewer EJ Jr, Bass J, Baum J, Cassidy JT, Fink C, Jacobs J, et al. Current proposed revision of JRA Criteria. JRA Criteria Subcommittee of the Diagnostic and Therapeutic Criteria Committee of the American Rheumatism Section of The Arthritis Foundation. Arthritis Rheum 1977;20:195-9.

18 Jorgensen C, Picot M, Bologna C, Sany J. Oral contraception, parity, breast feeding, and severity of rheumatoid arthritis. Ann Rheum Dis 1996;55:94-8.

19 Jara LJ, Lavalle C, Fraga A, Gomez-Sanchez C, Silveira LH, Martinez-Osuna P, et al. Prolactin, immunoregulation, and autoimmune disease. Semin Arthritis Rheum 1991;20: 273-84.

20 Whyte A, Williams RO. Bromocriptine supresses postpartum exacerbation of collagen induced arthritis. Arthritis Rheum 1998;31:927-8.

21 Medard L, Szamotulska K, Mielniczuk H. Pozakliniczne uwarunkowania podejmowania decyzji o cieciu cesarskim. Ginekol Pol 1997;68:22-8.

22 Brzezinski Z, Mazur J, Szamotulska K, Sawinska I. Umieralnosc okoloporodowa $i$ niemowlat oraz dzieci $i$ mlodziezy. Warsaw: Instytut Matki i Dziecka, 1966

23 Prieur AM, Le Gall E, Karman F, Edan C, Lasserre O, Goujard J. Epidemiologic survey of juvenile chronic arthritis in France. Comparison of data obtained from two different regions. Clin Exp Rheumatol 1987;5:217-23.

24 Gare BA, Fasth A. Epidemiology of juvenile chronic arthritis in southwestern Sweden: a 5-year prospective population study. Pediatrics 1992;90:950-8.

25 Ploski R, Forre O. Non-HLA genes and susceptibility to juvenile chronic arthritis. Clin Exp Rheumatol 1994;12 (suppl 10):S15-17.

26 Ploski R, Vinje O, Ronningen KS, Spurkland A, Sorskaar D, Vartdal F, et al. HLA class II alleles and heterogeneity of juvenile rheumatoid arthritis. $\mathrm{DRB} 1^{\star} 0101$ may define a novel subset of the disease. Arthritis Rheum 1993;36:46572 . 